\title{
Waste Management in Metropolitan Areas
}

\author{
Nicola Tucci ${ }^{1, a}$, Francesco Antonio Fagà ${ }^{2, b}$ \\ ${ }^{1}$ Via San Cristoforo 33, Reggio Calabria, Italia \\ ${ }^{2}$ Via anzaro 388046 Lamezia Terme \\ anicotucci73@gmail.com, bfaguss59@gmail.com
}

Keywords: Waste, Planning, Ambit, Metropolitan.

\begin{abstract}
The paper presents the study carried out by an association of municipalities north of the metropolitan area of Buenos Aires for the management of municipal solid waste (RSU). The research moves from the study of the state of the organization proposing the necessary managerial fixed. By setting goals thunderstorms is an integrated program designed to build a system capable of self-sufficient and self-sustainable waste management from the point of view of economics and finance.
\end{abstract}

\section{Introduction}

This pre-feasibility study prepared by the Centro Studi D.E.I (Desarrollo Etico Internaciònal) in collaboration with the Italian Chamber of Commerce in Buenos Aires aims to prefigure a course of study - research - design that will be useful to the Municipality of the Metropolitan Norte (AMN) to set about solving the issue management and treatment of waste in their territories.

This study starts from the direct observation by Expert DEI, local systems of waste management in the Province of Buenos Aires and, in particular, in the territorial area of the Rio Reconquista, which fall in the area 4 of the 5 Municipalities of AMN (Cuenca baja del Rio Reconquista).

Direct observation, it adds to the experience of the Centro Studi D.E.I. [1] in the search for innovative technological solutions and management standards and technologies developed on a European and Italian that can easily adapt to the realities of urban Argentine population densities are high, right from the search Italo-Argentine of has developed an integrated method of RSU management, composed of both systems, high-tech integrated systems of collection, which is registered with the trademark Argentalia ${ }^{\circledR}$.

This pre-feasibility study demonstrates, at the outset, that it is useful to explore the theme through a next step, in a real feasibility study that supports municipalities in AMN important choices to put in place concrete activities and virtuous in which the waste issues can move from the problem situation to that resource.

\section{The territorial ambit of the AMN}

The AMN (Metropolitan Area Norte) is geographically located north of CABA (Ciudad Autónoma de Buenos Aires) within the urban system and administrative defined as "Gran Buenos Aires" (GBA).

The AMN extends over 5 municipalities: San Isidro, San Fernando, Tigre. Vicente Lopez and Escobar. The territories of the first 4 municipalities listed above fall hydrographically, partly or wholly, in the "Cuenca" Rio Reconquista.

The AMN faces to the east, the Rio de La Plata, and the hydrographic system, its morphology is strongly influenced by the interactions between the Rio Reconquista and the great Rio de la Plata estuary, creating hydraulic phenomena significantly negative species in Tigre Partido.

The territory covers an area of about 1.570 square kilometers, with a population of 1.315 .538 inhabitants (Census 2010), with an average population density of 838 inhabitants / sq km, which is larger diversified among the various municipalities where stand the very high density demographic Vicente Lopez (7.978 inhabitants / square km) and San Isidro (5.694 inhabitants / km²). 
In the present system of management, the RSU products are delivered for big dump in the territory of the Municipality of General San Martin managed by CEAMSE (Coordinación Ecológica Area Metropolitana Sociedad del Estado).

The AMN overall are produced annually 386.854 tons of RSU ( municipal data 2012) with a per capita average daily production of $0.82 \mathrm{~kg} /$ inhabitant; municipal data on the production of RSU have a much diversification thrust between the data of the average daily production per capita Escobar (0.34 kg / inhabitant ) and San Isidro ( $1.29 \mathrm{~kg} /$ inhabitant ), which may be due to several factors such as the quality of the data and / or a different urban - industrial and social and / or with the presence of non-formal landfills ( Basurales Cielo Abierto ).

The feasibility study will evaluate these data, through direct analysis, also using the information provided by CEAMSE and provides a projection of the average figure in the urban area of the GBA [2]. In any case, at this stage, the data gives us the order of magnitude of an annual production of RSU total of between $400-450.00$ tons / year.

In the area there are 4 dell'AMN informal landfills (Basurales Cielo Abierto - BCA), surveyed by OPDS - Body Desarrollo Provincial Sustenible - the Province of Buenos Aires.

\section{Objectives}

Strategic objectives of this pre-feasibility study are to envisage at the outset :

$\checkmark$ a system of MSW management in the Metropolitan Area Norte (AMN) in the province of Buenos Aires, able to minimize the landfilling of RSU, passing through the enhancement of MSW recycling in the dry part in the production of energy from the treatment of wet part and an optimized system of waste collection;

$\checkmark$ a system that is sustainable both in terms of financial loss, both from an environmental perspective, including through the introduction of technological and management innovation to European standards;

$\checkmark$ a system capable of activating a production -related waste cycle and able to attract investments of internationalization.

Operational objectives of this pre-feasibility study are:

$\checkmark$ frame territorially the Metropolitan Area Norte (AMN);

$\checkmark$ estimate the order of magnitude of the waste management system of AMN and define an initial characterization of RSU in its composition;

$\checkmark$ illustrate, by way of expeditious, intervention methods for the design of a system for the management of RSU;

$\checkmark$ illustrate, by way of expeditious, the technologies to be adopted (plants) and their function in the system;

$\checkmark$ foreshadow a structure of the plant system;

$\checkmark$ estimate an income statement buoyancy of the system;

$\checkmark$ define goals and plan for the preparation of a subsequent feasibility study and determine the human and material resources to achieve it.

\section{The approach to planning and programming}

For the purposes of scheduling and planning of strategies, actions and interventions to be implemented to determine the integrated management of municipal solid waste, the Metropolitan Area Norte, which is able to solve the problem of a verse of the contributions and the 'capable of generating more economic resources, the three methods are shown here-designed by the Centro Studi DEI [3]. 
The method G.Ott.Ri.A.L. ${ }^{\circledR}$

\section{Optimized Management of Municipal Waste in Local Area}

Waste management should be approached with a flexible and integrated approach. A proper waste management can not be limited only to the technical aspect of the collection service, using separate methods, but must encompass both business planning and programming choices to implement that type of administration [5].

The method puts the basis for its action the integration of technical tools with administrative procedures, and proposes an approach of territorial and urban development and the structuring of services for the collection and transportation of municipal waste.

The method consists of interconnected phases for the implementation of the optimization of waste management at the local level:

$\checkmark$ regulatory framework;

$\checkmark$ analysis of local needs and characteristics of the flows of municipal waste ;

$\checkmark$ the structure of collection services;

$\checkmark$ infrastructure planning;

$\checkmark$ information;

\section{Regulatory framework}

Through the administrative regulation is necessary to create the conditions so that the various operational tools can be effective; create the framework within which different actors can operate and be punished when I put outside. The regulation must also take responsibility to prefigure activities aimed at the prevention of waste production.

Analysis of local needs and characteristics of the flows of municipal waste The analysis of spatial and urban planning is essential to understand the flow of waste. The analysis of spatial and urban planning is the basis for the determination and the contextualization of production flows, as well as the structuring of the services to be implanted and / or optimize and infrastructure to accomplish.

The structure of collection services

The structuring of collection services should be as more responsive to the needs expressed by the users in the area. Tend the services must assume a constant approach to users keeping in mind the economic sustainability. The services to be implanted and / or optimize must always be designed with a view to integration and turned to total territorial coverage is that the upstream components of the waste fractions.

\section{Territorial Infrastructures}

The local infrastructure is essential for the optimization of transfers, transportation and logistics. The territory is instrumental equipment necessary to implement the offer of transfer provision with collection services. Positive evolution may be the creation of infrastructure and supra local consortium level.

\section{Information}

The information, which must be continuous, is the channel that binds the dispenser of services (local administration ) with the users, therefore the information flow must be constant. Must provide information on the new regulations of services, initiatives implemented and stimulate utilities to good practice.

The structured system must be flexible and must have the intrinsic property do modulate respect to changes in the flow of production and land. The system should not be passive but dynamic. 
The method ARGENTALIA ${ }^{\circledR}$

The method Argentalia ${ }^{\circledR}$ is an integrated system for the management and treatment of waste and constitutes an advance management that integrates modern technologies of processing and enhancement with an advanced method of separate waste collection [4].

The strategic objectives are:

$\checkmark$ decrease the volume of waste that must be landfilled (the first goal is identified to $10.5 \%$ in the first phase, up to fall below 6\% within 3-5 years);

$\checkmark$ reduce the costs borne by society;

$\checkmark$ enhance the waste entering the market secondary raw materials and renewable energy, thereby increasing both the performance and profitability of the installations, and the competitiveness of the local industry.

The overall picture that the system constructs establish a cyclical path, so continuous, capable of enhancing waste by returning to the market in the form of products and raw materials. A route that changes the life of a product is now defined as " cradle to grave " to extend shelf life and instead sent to a cycle defined as " cradle to cradle ".

Argentalia ${ }^{\circledR}$ draws this new perspective not only intercepting the waste in a different manner and directing them to a new life, through its exploitation, but also taking action to lessen the waste production. The future of management goes through a systematic reduction of waste generation, waste collection extended to all villages, enhancement through the recovery of materials and energy production. In this view, the proposed system defines a pattern of action that is transferable and adaptable to different situations but with one common denominator: the waste is a resource.

The method ATLAS $+{ }^{\circledR}$

The method deals with objectively identify the most suitable location for waste treatment and utilization of municipal solid waste and is based on a matrix consequential set at three times the base, from which the guidelines to be followed for the applicability of the actual choices management.

However, the first and the second phase does not have a simple and unequivocal relationship to " cascade " that leads from the first to the second, but they have a two-way relationship of exchange data and interact with each other. All information collected in the analysis phase, leading to the diagnosis of the area and consequently to define the features, go through a series of special procedural filters that have the task to highlight some significant situations:

$\checkmark$ Areas where no intervention is not permitted;

$\checkmark$ Areas where several precautions must be taken before using them;

$\checkmark$ Areas in which the economic, social and environmental conditions are suitable for interventions.

This screening is used to determine the " primary vocations " of the territory and are substantially represented by varying degrees of compatibility with some types of intervention and various incompatibilities to use risky.

In Phase Project of the plan, are formed of " matrices " representing the ideal conditions in which to place the compatibility of the area. Comparing these " arrays " with real-life situations can be detected decipher the degree of non-calling or vocation of the area in question. All of this provides a tool that can be very correct and prevent errors, bad locations, uneconomic waste of resources, uses antisocial also limits the possibility of uncontrollable speculation, since the vocation and destination areas objectively results from the analysis process. For the purpose of comparative evaluation of the sites identified in the course of the first trial based on exclusionary factors and opportunities, a model has been developed that is based on criteria of sustainability. According to a conception invalsa now at the highest institutional levels, the latter is considered to be " resultant " of three different - but interrelated - real aspects associated with every choice and action : social, environmental and economic. 


\section{Reference}

[1] N. Tucci, F. Fagà: Il Metodo Argentalia. Innovazione tecnologica e integrazione gestionale in sistemi territoriali di gestione rifiuti urbani. In: Atti "call for papers" del seminario Scientifico "Rifiuti. Gli aspetti innovativi nella Ricerca scientifica e nella gestione ai vari livelli territoriali" a Cura dell’Università di Bologna - Polo Rimini - CTS Ecomondo ed altri; ECOMONDO RIMINI - Maggioli Editore nov (2013)

[2] F. Valotta, F. Fagà, N. Tucci: Gestión de residuos: una mirada sobre la provincia de Buenos Aires (Argentina). In: "Futuro Sustentable", Anno 9, N. 51 lug/ago, N.52 set/ott, N. 53 nov/dic (2013)

[3] N. Tucci, F. Fagà, F. Valotta: Le strategie innovative per la gestione dei rifiuti nella Provincia di Buenos Aires; in corso di pubblicazione su Rivista "RECYCLING" - Dicembre (2013)

[4] N. Tucci, F. Fagà, F. Valotta: La Provincia di Buenos Aires, un'altra gestione dei rifiuti. In: "L'ambiente", I.C.S.A. Edizioni, Milano, anno XX, N. 2, Marzo/Aprile (2013)

[5] N. Tucci, F. Fagà, F. Valotta: RIFIUTI E RICICLAGGIO - Quando il Sud Italia diventa esempio per il Sud America - Implementazione di una gestione locale dei rifiuti. In: “RECYCLING”, PEI srl Editore, Parma, Anno 17, N. 2 , Marzo 2013 pp. 24 - 28 